\title{
Influência de um Blog no Ensino de Ventilação Mecânica na Disciplina de Enfermagem no Cuidado a Pacientes de Risco
}

\author{
João Carlos Krause ${ }^{1}$ \\ Dante Saul Braun² \\ Antonio Vanderlei dos Santos ${ }^{3}$ \\ Rosane Teresinha Fontana ${ }^{4}$
}

\begin{abstract}
Resumo
Uma das motivações deste estudo foi avaliar o objeto de aprendizagem em forma de um blog no processo ensino/aprendizagem na disciplina de Enfermagem no Cuidado a Pacientes de Risco, ao abordar o assunto ventilação mecânica. Utilizou-se uma metodologia quantitativa para coleta e análise dos dados, baseada na aplicação de questionários e observações das respostas obtidas. A melhor compreensão do tema ventilação mecânica faz-se necessária, visto 0 grau de complexidade do conteúdo. Para o estudante de Enfermagem, é de suma importância a aceitação dos saberes desse conteúdo para melhor atender seu paciente em uma Unidade de Terapia Intensiva. Os resultados encontrados foram satisfatórios, uma vez que 0 uso do blog no estudo proporcionou uma aprendizagem significativa para os acadêmicos.
\end{abstract}

Palavras-chave: Ambiente virtual de aprendizagem. Blog. Ventilação mecânica.

${ }^{1}$ Licenciatura Plena em Física (UFSM), Mestrado em Física Teórica (UFSC) e Doutorado em Ciências (UFRGS). Professor Tempo Integral - DCET - URI - Santo Ângelo. Subcoordenador PPGEnCT Mestrado Profissional. krause@santoangelo.uri.br

2 Graduação em Fisioterapia (Unicruz), Especialista em Urgência Emergência e Trauma (Unijuí), Especialista em Terapia Intensiva (Profísio - Curitiba - PR) e Mestre em Ensino Científico e Tecnológico (URI). Coordenador do serviço de Fisioterapia e da Unidade de Terapia Intensiva do Hospital Regional Unimed Missões - Santo Ângelo - RS. dante.braun@hotmail.com

${ }^{3}$ Licenciatura Plena em Física (UFSM), Mestrado em Física Teórica (UFSC) e Doutorado em Ciências (UFRGS). Professor tempo integral - DCET - URI - Santo Ângelo. Chefe Departamento de Ciências Exatas e da Terra - DCET. vandao@san.uri.br

${ }^{4}$ Graduação em Enfermagem(Unisinos), Graduação em Ciências (URI), Especialista em Saúde Coletiva (Unicruz), Mestrado e Doutorado em Enfermagem (UFRGS). Professora tempo integral - DCS URI - Santo Ângelo. Docente permanente PPGEnCT. Servidora pública da secretaria do Estado do Rio Grande do Sul - Núcleo Regional de Educação em Saúde Coletiva. rfontana@san.uri.br 
INFLUENCE OF A BLOG IN THE TEACHING OF MECHANICAL VENTILATION IN THE NURSING DISCIPLINE IN THE CARE OF RISK PATIENTS

\begin{abstract}
One of the motivations of the study was to evaluate the learning object in the form of a blog in the teaching and learning process in the discipline of Nursing in the Risky Patients Care, when addressing the subject Mechanical Ventilation. A quantitative methodology was used to collect and analyze data, based on questions application and observations of the answers from such application. The best understanding of the topic Mechanical Ventilation is necessary, given the complexity degree of the content. For Nursing students, the acceptance of the knowledge of such content has utmost importance, for a better attendance to a patient in an Intensive Therapy Unit. The results found were satisfactory, since the use of the blog in the study has provided a significant learning for the academics.
\end{abstract}

Keywords: Virtual learning environment. Blog. Mechanical ventilation.

Recebido em: 18/5/2017

Aceito em: 24/10/2017 
Um breve retrospecto do desenvolvimento da tecnologia da informação permite distinguir pelo menos dois momentos importantes, os quais se sobrepõem e ainda estão plenamente vigentes. Um deles é o que se inicia com o advento do computador e tem seu ponto mais alto com o surgimento do Personal Computer (PC), cujo aperfeiçoamento está longe de ser concluído. O segundo começa com as primeiras redes de comunicação que utilizam computadores conectados a um servidor central e desenvolve-se até o ponto atual da World Wide Web (WWW), ou seja, a rede mundial de computadores (MELLO, 2004).

Considerando que na sociedade atual os recursos das Tecnologias da Informação e Comunicação (TICs) estão cada vez mais presentes, espera-se um aumento no uso das TICs na educação, mesmo considerando que esta ainda caminhe timidamente no uso desses recursos. Isto é claramente observado no dia a dia do meio escolar, em que predominam as aulas tradicionais, e isto pode ser explicado não apenas por uma certa dificuldade de os docentes apropriarem-se dessas tecnologias ou pela complexidade no processo de elaboração de conteúdos didáticos para esse novo cenário, mas também pela ausência de uma formação continuada eficiente na área para estes professores. Se tais problemas fossem solucionados, essas tecnologias poderiam ser empregadas de forma eficiente como instrumentos para auxiliar o professor a criar novas estratégias de ensino que poderiam favorecer a apropriação do conhecimento por parte do aluno (BRAGA et al., 2012).

Em 20 anos, as tecnologias digitais progrediram significativamente, alterando, em muito, a vida das pessoas. E, ao que parece, escola não está caminhando na mesma direção, visto que muitas pesquisas demonstram uma relativa resistência à mudança dos sistemas escolares. Há indicativos, porém, mesmo que insipientes, de que está próximo o que se poderia chamar de "uma 'tempestade perfeita', ou seja, a combinação de uma série de fatores que poderiam acabar dando lugar, finalmente, a uma janela aberta de oportunidades para uma mudança pedagógica", utilizando o potencial da tecnologia para qualificar a produtividade na educação. Tais fatores envolvem a grande incorporação das tecnologias para usos sociais e de comunicação entre os adolescentes e crianças; a propagação de muitas empresas que oferecem serviços de valor agregado como 
conteúdos e, certamente, aplicativos educacionais, além da quase universalização de dispositivos de uso individual, como tablets e smartphones, ao alcance de uma proporção muito elevada de alunos e docentes (FRANCESC, 2016, p. 19).

É visível que a informática deixou de ser apenas uma presença a mais nas escolas, tornando-se meio de comunicação cada vez mais essencial ao educador e ao educando. Não é mais apenas solicitado que o professor conheça a sua área, mas ele também deve saber trabalhar e lidar com a tecnologia que o rodeia, não apenas apresentada para os alunos em sala de aula, mas utilizando-a fora do ambiente escolar. Constitui uma ferramenta tanto de gestão como também de avaliação do próprio objeto de aprendizagem pelos alunos que o utilizam, uma vez que ele está localizado no contesto de ensino/aprendizagem. São exigidas novas competências profissionais, para o uso da tecnologia do computador pessoal, no escritório ou em casa, que, de dia para dia, se intensifica. Emerge de forma revolucionária a Internet, favorecendo a interatividade no campo empresarial e educacional (NUNES et al., 2010, p. 245).

A formação tecnológica dos professores também já vem sendo estudada de forma específica por alguns autores, mostrando, assim, que a formação de novos professores passa por um novo contexto, ou seja, sua inserção no mundo das novas tecnologias (MARIM; FREITAS; SANTOS, 2014). A tecnologia, contudo, por si só não garante que ocorram melhorias na aprendizagem; para tanto, precisamos realizar uma avaliação. Alguns autores consideram a avaliação como produção de sentidos, uma prática social; portanto, relaciona-se com a ética e está carregada de valores. No nosso caso escolhemos realizar uma autoavaliação do objeto de aprendizagem, coletando dados de como foi a satisfação dos alunos ao usá-lo (DIAS SOBRINHO, 2009). Assim, deve-se pensar em utilizar as novas tecnologias como uma ferramenta avaliativa. Por outro lado, a avaliação deve ser confiável e crítica, mas sempre permitindo novos sentidos e, assim, proporcionando novas interpretações e melhorias ao sistema em avaliação.

$\mathrm{Na}$ área da Enfermagem, as estratégias tecnológicas de ensino-aprendizagem encontram-se em franco desenvolvimento, embora a produção sobre tecnologias educacionais na área tornou-se expressiva somente a partir do ano de 2008 (ROCHA; OLIVEIRA; ESTEVES, 2015). Estes estudos assinalam avanços 
da área da saúde na construção e validação de objetos virtuais de aprendizagem, e neste sentido, buscou-se pesquisas relativas à elaboração de Objetos de Aprendizagem (OAs) desenvolvidos para a área da saúde. Observou-se que eles estão, em geral, disponibilizados via Web, incorporados ou não a um ambiente virtual de aprendizagem e são considerados facilitadores desse processo, apresentados em forma de livro eletrônico, animação, simulação, questionários de avaliação ou autoavaliação. Dos trabalhos publicados em periódicos nacionais, mais da metade é originada da Região Sul e a maioria envolve discentes da área da Enfermagem. Os OAs quase em sua totalidade versam sobre educação em saúde, tecnologias em saúde e/ou tecnologia digital. Os autores assinalam que a utilização de objetos virtuais de aprendizagem, por si só, não garante a aprendizagem. Para que ela seja significativa devem ser propostos métodos que estimulem a iniciativa e a responsabilidade do aluno em relação ao seu próprio aprendizado, junto ao comprometimento crítico e criativo do docente (TRINDADE; DAHMER; REPPOLD, 2014; CALIL et al., 2012; GUERRA et al., 2014).

Diante disso, investir em cursos que ensinem/atualizem professores para o uso de mídia social no ensino de Enfermagem e otimizar um ambiente de aprendizado colaborativo, para oferecer elementos que auxiliem o professor no ajuste de suas abordagens pedagógicas, adequando-se ao novo aluno, pode agregar valor ao processo ensino/aprendizagem na área (SALMINEN et al., 2016).

\begin{abstract}
A busca da inovação no ensino, pela adoção de práticas educativas que possibilitem ao estudante: um papel ativo na construção do conhecimento; a resolução de problemas do contexto da prática profissional; a reflexão sobre a própria prática; o questionamento às teorias; o cotejo entre as teorias e os dados de realidade resultantes de pesquisas desenvolvidas no contexto formativo (SOARES, 2013, p. 227).
\end{abstract}

A motivação que nos levou a realizar esse estudo foi propor uma estratégia que agregasse valor ao processo ensino - aprendizagem, utilizando-se a autoavaliação como norteador pedagógico. Assim, a base deste trabalho foi apresentar um objeto de aprendizagem com a proposição de um blog, como facilitador e como forma de coletas de dados para, ao final do processo, realizar a avaliação do próprio blog como ferramenta relativa ao processo ensino/aprendizagem de 
conceitos relacionados à ventilação mecânica na disciplina de Enfermagem no Cuidado a Pacientes de Risco. O questionamento motivador para esta proposta foi: Qual a influência de um blog no processo ensino/aprendizagem de conceitos de ventilação mecânica na disciplina de Enfermagem no Cuidado a Pacientes de Risco?

A seguir, apresentamos alguns aspectos básicos da fundamentação teórica na qual este estudo se baseia, tratando de objetos de aprendizagem construídos utilizando a aprendizagem significativa, como o seu pressuposto básico, assim como uma base relacionada à Unidade de Terapia Intensiva (UTI) e uma sucinta introdução sobre ventilação mecânica. Na sequência, uma descrição da metodologia com seus requisitos fundamentais, seguida da apresentação do produto educacional. Finalizando, apresenta-se e discute-se os resultados deste estudo, seguidos pelas considerações finais.

\section{Objetos de Aprendizagem}

A inclusão das Novas Tecnologias de Informação e Comunicação (NTICs) em quase todos os ambientes na atualidade coloca-nos diante de um momento em que a informática e, sobretudo a Internet, constituem-se uma realidade sem volta, reconfigurando nosso cotidiano. Na educação esse processo não é diferente. Um dos recursos tecnológicos empregados na área da educação são os Objetos de Aprendizagem (OAs), ou seja, materiais educacionais com objetivos pedagógicos que servem para apoiar o processo de ensino-aprendizagem (TAROUCO et al., 2004). Além desta terminologia, encontramos nas diferentes bibliografias as seguintes expressões: objetos educacionais, conteúdos de objetos compartilháveis, objetos de conhecimento, objetos de comunicação, objetos de aprendizado, entre outras (AUDINO, 2012; CARNEIRO; SILVEIRA, 2014; ALVAREZ; SASS, 2011; TRINDADE; DAHMER; REPPOLD, 2014).

Os OAs podem ser definidos também como recursos suplementares ao processo de aprendizagem, podendo ser reusados para apoiar o processo de ensino. O termo OA aplica-se de uma forma geral a materiais educacionais produzidos em conjunto com objetivo de maximizar as situações de aprendizagem 
em que o recurso pode ser utilizado. A ideia é que os OAs sejam montados como blocos com os quais serão construídos os contextos de aprendizagem (FABRE; TAMUSIUNAS; TAROUCO, 2003).

A estrutura do Objeto de Aprendizagem deve ter uma informação externa para facilitar o armazenamento, identificação e recuperação. Pode ser digital ou não digital, usado para a aprendizagem, educação ou formação. Pode ser um componente digital de material educativo e seu conteúdo deve ser facilmente identificável e endereçável, e cujo potencial principal seja a reutilização em diferentes contextos aplicáveis à educação virtual. Uma abordagem dirigida para a construção de OA permite que todos os recursos humanos, físicos e tecnológicos possam contribuir para o seu desenvolvimento como uma vantagem competitiva dentro do propósito da missão da organização (RENGIFO et al., 2015).

De acordo com Wiley (2000), Objeto de Aprendizagem é "qualquer entidade digital, que pode ser usada, reusada ou referenciada durante um processo de aprendizagem apoiado pela tecnologia". Os OAs podem ser desenvolvidos de várias formas, sem seguir regras ou padrões, contudo para garantir que os OAs sejam eficazes para o aprendizado e possam ser reutilizados, parcial ou integralmente, para atividades, esses devem ser produzidos segundo critérios e processos tecnológicos e pedagógicos.

Braga et al. (2012) ainda relatam que no âmbito da educação, o uso de OAs que não cumprem os objetivos pode ser algo catastrófico, pois podem ensinar erroneamente um determinado conteúdo. Já no âmbito computacional, um $\mathrm{AO}$ que possui problemas técnicos pode contribuir para a desmotivação do aluno. Um OA ideal seria aquele que tivesse um equilíbrio técnico e pedagógico e que pudesse ser frequentemente reutilizado e contribuir de maneira efetiva para o aprendizado.

Atualmente, os Objetos de Aprendizagem são encarados com grande importância no processo de ensino e aprendizagem, fornecendo a capacidade de simular e animar fenômenos e reutilizá-los em vários outros ambientes desse processo. Apesar de constituírem uma proposta recente no sistema educacional brasileiro e também mundial, inúmeras publicações e conceitos sobre a temática já podem ser evidenciados; no entanto, eles ainda não apresentam um consenso 
universalmente aceito a respeito de sua definição. Quando há referência a Objetos de Aprendizagem, logo são associados ao uso do computador e à utilização da Internet (AUDINO, 2012).

Um Objeto de Aprendizagem, no entanto, é todo aquele que é utilizado como meio de ensino/aprendizagem. Um cartaz, uma maquete, uma canção, um ato teatral, uma apostila, um filme, um livro, um jornal, uma página na Web, podem ser Objetos de Aprendizagem. A maioria destes objetos pode ser reutilizada, modificada ou não e servir para outros objetivos que não os originais. Em muitas escolas existe aquele famoso depósito, nem sempre muito organizado, no qual se guardam objetos que fizeram parte de aulas e projetos. Um depósito de onde se recuperam estes objetos para reutilização, modificação, até que o desgaste inviabilize novas transformações e utilizações (GUTIERREZ, 2004, p. 6).

Embora existam vários conceitos relacionados aos Objetos de Aprendizagem, todos voltam sua atenção para a construção do conhecimento, por meio dos mais variados recursos. Nesse sentido, os autores concordam que, para que ocorra uma plena aprendizagem é necessária uma reorganização de conceitos aprendidos, gerando novos significados. A aprendizagem significativa vem ao encontro destes conceitos, concordando com a inserção do blog como facilitador dessa aprendizagem.

Conforme Marinho (2007), blog é chamado atualmente daquilo que anteriormente fora o weblog, termo este conhecido em 1997. Provém de web $+\log$, sendo que $\log$ representa um registro e web diz respeito à teia que é a Internet; ou seja, é uma forma de fazer registro na Internet. Seria uma versão eletrônica do diário, uma forma de registro adotada há tempos, notadamente por jovens do sexo feminino, que guardava reflexões e pensamentos mais acanhados e inacessível a outras pessoas. Agora, no tempo da pós-modernidade, quando as fronteiras entre o público e o privado ficam cada vez mais tênues, a exposição pública do que é pessoal, por meio do blog, envolve cada vez mais pessoas, notadamente jovens. Progressivamente, os blogs vão se transformando em um útil e versátil instrumento de rápida difusão de informações na Web. Um 
exemplo disso está no jornalismo eletrônico, que surgiu há algum tempo. Hoje, blogs de jornalistas conceituados constituem a forma de acesso instantâneo à notícia do último momento.

Uma importante questão dos blogs atualmente está no fato de que qualquer pessoa pode criar um, uma vez que a tecnologia empregada para sua criação e publicação é muito simples; tendo um pequeno domínio de uso do computador pode-se criar e manter um blog. A facilidade de se criar o blog, a possibilidade de fazê-lo sem custo e sem um domínio de linguagem de programação HTML, contribuíram para a sua explosão na Internet. Os blogs são um meio para que pessoas se comuniquem com outras, tendo como base ou ponto de convergência seus interesses ou a simples curiosidade. Eles são, hoje, parte de uma crescente conjunção de ferramentas de comunicação pessoal e de informação (MARINHO, 2007).

Os blogs são ferramentas relativamente novas no cenário mundial e nacional. $\mathrm{O}$ primeiro deles surgiu aproximadamente na segunda metade da década de 90, criado por Tim Berners-Lee, intitulado "O que há de novo?" No Brasil, os primeiros registros de blogs foram o da gaúcha Viviane Menezes, intitulado "Delights to Cheer"; do santista Renato Pedroso Junior ou Nemo Nox, denominado "O Diário da Megalópole". Foi há bem pouco tempo que os blogs começaram a ser usados com fins educacionais. Para Marinho (2007), entre os fenômenos interativos enquadrados nos princípios da Web 2.0, estão os componentes da blogosfera (blogs, videologs, fotologs e audiologs), entre outras ferramentas.

\section{Aprendizagem Significativa}

A construção do conhecimento ocorre quando deliberadamente se realizam articulações entre o que se conhece e a informação nova que é absorvida. Essa estrutura cognitiva se dá ao longo da vida por meio de uma sequência de eventos de forma idiossincrática; ou seja, ocorre individualmente. Nesse aspecto, vem à tona a estrutura do construtivismo, chamado genericamente desta forma pelo entendimento de como se constrói a estrutura cognitiva da pessoa ao longo 
da vida. Piaget e Vygotsky foram os grandes precursores do construtivismo contemporâneo, iniciando os trabalhos em 1920, no entanto somente em 1960 as ideias construtivistas foram utilizadas com maior ênfase (TAVARES, 2004).

Para esclarecer como é produzida a aprendizagem escolar, Ausubel (apud PELIZZARI et al., 2002) propôs distinguir dois eixos diferentes que originariam as diversas classes de aprendizagem, a Aprendizagem significativa e a Aprendizagem memorística. O primeiro eixo tem relação com a maneira de organizar o processo de aprendizagem e a estrutura em torno da dimensão aprendizagem por descoberta/aprendizagem receptiva. Isso se refere à maneira como o aluno recebe as informações que deve aprender; ou seja, quanto mais se aprende por descoberta, mais o conteúdo é recebido de forma não acabada e o mesmo deve definir ou descobrir, antes de assimilá-lo. Por outro lado, quanto mais receptivo for o conteúdo, mais eles são repassados ao aluno em forma final, já acabada. $O$ segundo eixo remete ao tipo de processo que intervém na aprendizagem e origina um continuиm delimitado pela aprendizagem significativa, por um lado, e pela aprendizagem mecânica ou repetitiva, por outro. Nesse caso, quanto mais se relaciona o novo conteúdo de maneira substancial e não arbitrária com a estrutura cognitiva prévia que lhe for relevante, mais próxima será a aprendizagem significativa. Quanto menos se estabelece esse tipo de relação, mais próxima se está da aprendizagem mecânica ou repetitiva (PELIZZARI, 2002).

No entendimento de Moreira (2013), a aprendizagem significativa é aquela em que ideias expressas simbolicamente interagem de maneira substantiva e não arbitrária com aquilo que o aprendiz já sabe. Substantiva quer dizer não literal, não ao pé-da-letra, e não arbitrária significa que a interação não é com qualquer ideia prévia, mas sim com algum conhecimento especificamente relevante já existente na estrutura cognitiva do sujeito que aprende. A esse conhecimento, especificamente relevante à nova aprendizagem, podendo ser um símbolo já significativo, um conceito, uma proposição, um modelo mental, uma imagem, David Ausubel chamava de subsunçor ou ideia-âncora; ou seja, é o nome que se dá a um conhecimento específico, existente na estrutura de conhecimentos do indivíduo, que permite dar significado a um novo saber que lhe é 
apresentado ou por ele descoberto. Tanto por recepção como por descobrimento, a atribuição de significados a novos conhecimentos depende da existência de saberes prévios especificamente relevantes e da interação com eles. ${ }^{5}$

A aprendizagem é muito mais significativa à medida que o novo conteúdo é incorporado às estruturas de conhecimento do aluno e adquire significado para ele a partir da relação com seu conhecimento prévio. Ao contrário, ela se torna mecânica ou repetitiva, uma vez que se produziu menos essa incorporação e atribuição de significado, e o novo conteúdo passa a ser armazenado isoladamente ou por meio de associações arbitrárias na estrutura cognitiva. Quando o conteúdo escolar a ser aprendido não consegue ligar-se a algo já conhecido, ocorre o que Ausubel denomina de aprendizagem mecânica; ou seja, quando as novas informações são aprendidas sem interagir com conceitos relevantes existentes na estrutura cognitiva. Assim, a pessoa decora fórmulas, não havendo aprendizagem significativa e o uso do conceito em outras áreas (PELIZZARI et al., 2002).

Entende-se que um objeto de aprendizagem não pode ser meramente um dispositivo tecnológico que venha a ser montado de qualquer forma, mas um instrumento elaborado dentro de uma teoria de aprendizagem. Usa-se, portanto, a aprendizagem significativa para montar o objeto de aprendizagem em forma de blog, que foi utilizado na educação em saúde e também como uma ferramenta de autoavaliação, no sentido de recolhermos informações sobre a aceitação do próprio blog. É válido sublinhar que não estamos avaliando os conceitos discutidos no blog, sobre os conteúdos de ventilação mecânica, e seus conceitos básicos.

${ }_{5}$ O subsunçor pode ter maior ou menor estabilidade cognitiva, pode estar mais ou menos diferenciado, ou seja, mais ou menos elaborado em termos de significados. Como o processo, contudo, é interativo, quando serve de ideia-âncora para um novo conhecimento ele próprio se modifica adquirindo novos significados, corroborando significados já existentes (MOREIRA, 2013, p. 6). 


\section{Ventilação Mecânica}

Muitas foram as etapas de surgimento e evolução da ventilação mecânica, todavia, o marco principal dessa evolução deu-se no período após a Segunda Guerra Mundial. Até meados de 1950 a ventilação por pressão intermitente, por intermédio do pulmão de aço, continuou tendo ampla utilização (JERRE, 2009).

$\mathrm{Na}$ década de 60 começaram a surgir os aparelhos respiradores de pressão positiva, ciclados pela pressão e, na década de 70, apareceram os aparelhos ciclados a volume e a fluxo (da série de Bird e Mark). Na década de 80 importantes avanços tecnológicos permitiram a construção de aparelhos extremamente complexos. A partir dessa década até os tempos atuais, surgiram outros aparelhos microprocessados, como o Servo®. Este é um ventilador mecânico invasivo que opera com pressão positiva, utilizado em Unidades de Terapia Intensiva (UTI) adulta e pediátrica, com objetivo de substituir a bomba mecânica de entrada e saída de ar promovendo uma melhor oxigenação aos tecidos corporais. Apresenta os modos ventilatórios controlados e assisti-controlados, como a ventilação mandatória intermitente sincronizada (SIMV), a ventilação controlada à pressão $(\mathrm{PCV})$, a ventilação controlada a volume (VCV) e modos assistidos para desmame da ventilação mecânica, como pressão positiva contínua na via aérea (CPAP) e ventilação por pressão de suporte (PSV). A manipulação deste ventilador é realizada por médicos, fisioterapeutas e enfermeiros qualificados para atender às demandas ventilatórias dos pacientes internados em UTI. Seu funcionamento depende de regulação de parâmetros ventilatórios como volume, pressão, frequência respiratória, pressão de final da expiração, quantidade de oxigênio e outros parâmetros necessários para suprir as necessidades de cada paciente (YAMASHIRO, 2017). Atualmente o objetivo principal da ventilação mecânica está voltado para a preservação da microestrutura pulmonar, com papel fundamental no restabelecimento da função pulmonar (COSTA, 2004).

O principal objetivo da ventilação mecânica é promover o repouso da musculatura respiratória e reduzir o trabalho da ventilação. Para um melhor relaxamento da musculatura inspiratória, o ventilador deverá ciclar em sincronia com a atividade do próprio ritmo respiratório do paciente (KNOBEL, 2004). 
Classifica-se o suporte ventilatório em dois grandes grupos: ventilação mecânica invasiva e ventilação mecânica não invasiva. Nas duas situações a ventilação artificial é conseguida com a aplicação de pressão positiva nas vias aéreas. A diferença entre elas fica na forma de liberação de pressão: enquanto na ventilação invasiva utiliza-se uma prótese introduzida na via aérea, isto é, um tubo oro ou nasotraqueal (menos comum) ou uma cânula de traqueostomia, na ventilação não invasiva utiliza-se uma máscara como interface entre o paciente e o ventilador artificial (CARVALHO; FRANCA; TOUFEN JUNIOR, 2007).

O suporte ventilatório atual visa ao conforto do paciente; então, deve haver manutenção da melhor interface possível entre este e o ventilador mecânico. A manutenção da ventilação e oxigenação do paciente deve estar em níveis adequados, de acordo com o exigido pela fisiopatologia da doença (ZAMBONI, 2006).

A ventilação mecânica é comumente empregada nos Centros de Tratamento Intensivo, mas sua utilização pode oferecer riscos aos pacientes. Suas principais complicações incluem lesão traqueal, barotrauma e/ou volutrauma, diminuição do débito cardíaco e toxicidade pelo uso do oxigênio. Esses pacientes também tendem a acumular secreções respiratórias, devido à tosse ineficaz ocasionada pelo tubo orotraqueal. Essa retenção de secreção contribui para hipoxemia, atelectasia e pneumonia, associadas ao ventilador (ROSA et al., 2007).

Após uma fundamentação teórica abordando temas como objetos de aprendizagem e aprendizagem significativa e, servindo-se desses para facilitar o processo de ensino-aprendizagem em ventilação mecânica em terapia intensiva, é que se passa a desenhar metodologicamente este estudo, método descrito a seguir.

\section{Metodologia}

Este estudo, segundo Gil (1999), caracteriza-se como uma pesquisa de abordagem quantitativa de caráter exploratório e descritivo. 
A população foi constituída por acadêmicos do oitavo semestre de um curso de Enfermagem de uma universidade regional situada no Noroeste do Estado do Rio Grande do Sul, da disciplina de Enfermagem no Cuidado a Pacientes de Risco, de ambos os gêneros, que espontaneamente aceitaram fazer parte da pesquisa após a assinatura do Termo de Consentimento Livre e esclarecido (TCLE). Participaram 14 acadêmicos do curso, sendo 9 do gênero feminino e 5 do gênero masculino. Este estudo foi realizado conforme os aspectos éticos contidos na resolução 466, de 12 de dezembro de 2012 do Conselho Nacional de Saúde, que trata da pesquisa envolvendo seres humanos. A pesquisa foi aprovada perante o Comitê de Ética em Pesquisa da Universidade Regional Integrada do Alto Uruguai e das Missões, sob o parecer número 1.535.970.

Após a autorização da instituição para a realização da pesquisa, foi ministrada aos acadêmicos participantes uma aula expositiva, relacionada ao tema "Ventilação Mecânica em UTI", contendo histórico da ventilação mecânica, física e mecânica de fluidos, anatomia respiratória, fisiologia da mecânica ventilatória, tipos de ventilador mecânico, ventilação por pressão positiva e pressão negativa, modos de ventilação mecânica, parâmetros da ventilação, imagens e vídeos de ventiladores em funcionamento.

Após a exposição, foi apresentado aos acadêmicos o blog contendo informações referentes ao conteúdo de "Ventilação Mecânica". Essas informações compreendem materiais como videoaulas e animações. $\mathrm{O}$ blog pode ser acessado livremente e a qualquer momento ou local. A produção do blog foi realizada por um dos autores e o seu conteúdo conta com assuntos relacionados à teoria sobre parâmetros de ventilação mecânica, simulador de ventilação mecânica, fisiologia respiratória-mecânica pulmonar, prática de intubação endotraqueal, intubação em pulmão animal, aula teórica de modos de ventilação, aula prática de parâmetros de ventilação e, finalizando, com uma apresentação do autor do blog.

Após a aula, para avaliar a influência da mídia eletrônica na aprendizagem sobre o tema, foi aplicado, aos participantes da pesquisa, um instrumento contendo oito questões, das quais sete de perfil quantitativo e uma descritiva. As 
questões foram respondidas de acordo com Escala Likert: Discordo Totalmente (DT), Discordo (D), Não Concordo Nem Discordo (NCND), Concordo (C), Concordo Totalmente (CT), na ordem em que estão apresentados.

As respostas objetivas foram analisadas utilizando-se a estatística descritiva por meio da distribuição da frequência e a resposta descritiva foi analisada mediante a análise das falas dos respondentes.

\section{O Objeto de Aprendizagem}

A opção pelo blog como produto educacional baseou-se na teoria de aprendizagem significativa e na prática docente dos pesquisadores, assim como na trajetória acadêmica discente, dependendo e utilizando essa ferramenta educacional como facilitadora no processo ensino-aprendizagem de conteúdos com certo grau de dificuldade.

Optou-se pela escolha desta ferramenta também, por ser de fácil empregabilidade, dispor de interface agradável e ser bem didática, além de ser de fácil acesso e permitir a postagem desde de um simples texto até construções complexas.

Após a aula presencial de ventilação mecânica ministrada aos acadêmicos, usando aprendizagem significativa, foram abordados os conceitos básicos de ventilação mecânica, utilizando os subsençores dos alunos, fazendo conexões entre os conceitos novos e os já consolidados pelos discentes. Foi apresentando o blog e deixou-se livremente o acesso, horário e data a cargo dos alunos.

A Figura 1 apresenta a imagem da página de abertura do blog, o qual conta com 8 postagens relacionadas à ventilação mecânica. Nas postagens há o registro de materiais práticos e teóricos em forma de vídeo, aulas teóricas, videoaulas práticas e materiais em formato PDF, assim como a apresentação e boas-vindas aos visitantes, por parte do autor do blog. Todas as postagens direcionam o visitante diretamente para o material em questão. As postagens são de caráter livre, podendo ser consultadas a qualquer momento ou local, bastando 
ter acesso à Internet. Todo o post de vídeos tem origem no YouTube, e foi feito o uso de links para o seu acesso. Segue-se a imagem que irá aparecer na tela do computador ao acessar o blog.

Figura 1 - Imagem da página inicial do blog

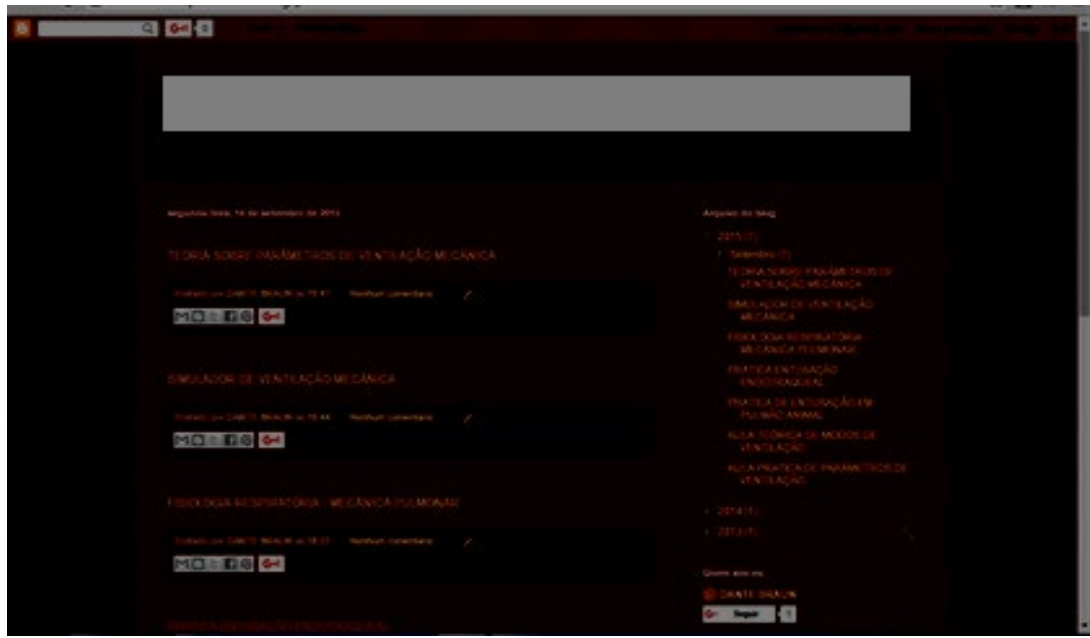

Fonte: http://dantefisioterapiaintensiva.blogspot.com.br

\section{Resultados}

Participaram do estudo 14 estudantes de ambos os gêneros, 9 (64\%) femininos e 5 (35\%) masculinos, seguindo uma tendência de a maior parte dos acadêmicos da maioria dos cursos da área da saúde ser do gênero feminino. Da totalidade dos participantes, somente $6(42 \%)$ responderam à questão 8 , sugerindo melhorias para o objeto de aprendizagem - blog. Os participantes da pesquisa estão nomeados em ordem numérica de 1 a 14, sendo identificados de forma aleatória, com M para o gênero masculino e F para o gênero feminino (ex: 1-M). 
Dos 6 (seis) participantes da pesquisa que responderam à questão descritiva, 4 (67\%) são do gênero masculino e 2 (33\%) indivíduos do gênero feminino. O restante dos participantes não apresentou nenhuma sugestão, deixando em aberto a questão 8 .

Os resultados para as questões de 1 a 7 estão representados no Gráfico 1. Observa-se que os termos Discordo Totalmente (DT) e Discordo (D) não apareceram nas respostas e desta forma foram suprimidos do gráfico.

Gráfico 1 - Gráfico referente as respostas das questões 1 a 7

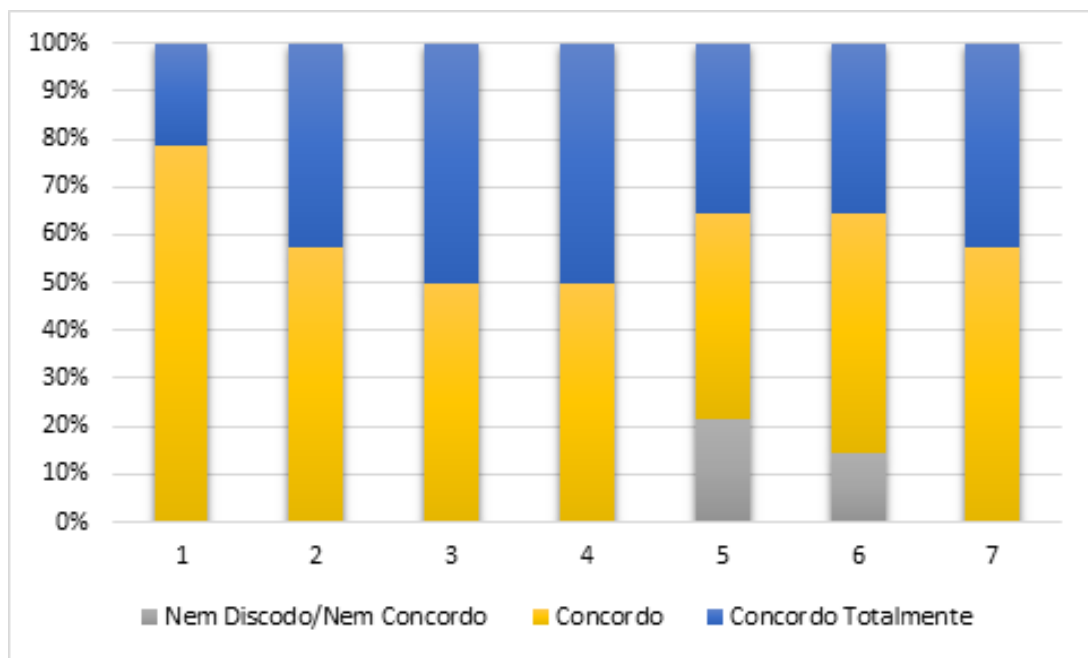

Fonte: Os autores.

Quando os participantes foram questionando se os conteúdos do blog estão claros e objetivos (questão 1), verificamos a ocorrência de 11 (79\%) respostas concordando com a questão e 3 (21\%) concordando totalmente.

Para a questão 2, que perguntava se as informações do blog estão apresentadas de forma didática, verificou-se a ocorrência de 8 (57\%) respostas concordando e 6 (43\%) concordando totalmente. As respostas dos estudantes a esta pergunta relacionamos à facilidade de compreensão dos conteúdos ministrados. 
Com relação à pergunta se o blog auxiliou na compreensão dos conteúdos de ventilação mecânica em UTI na questão 3, houve uma igual distribuição entre as respostas "concordo" e "concordo totalmente", ocorrendo 7 (50\%) respostas para cada opção.

$\mathrm{Na}$ questão 4 foi questionado se o estudante considerou o objeto de aprendizagem útil no processo ensino/aprendizagem e verificou-se a ocorrência das mesmas respostas da questão anterior, ou seja, 7 (50\%) respostas para "concordo" e 7 (50\%) para "concordo totalmente".

Ao analisar as respostas das questões 5 e 6 , que diz respeito à indicação do blog para colegas e outros conteúdos e disciplinas, pode-se observar pelo gráfico o surgimento de $3(\sim 21 \%)$ respostas "nem concordo nem discordo" para a questão 5 e $2(\sim 14 \%)$ para a questão 6 . Para a questão 5 houve uma ocorrência maior da resposta "concordo" (57\%), seguido de 5 (36\%) respostas de "concordo totalmente". Já para a questão 6 há ocorrência de 7 respostas $(50 \%)$ "concordo" em comparação com $5(\sim 36 \%)$ respostas de "concordo totalmente".

Ao observar as respostas para a questão 7 verifica-se a plena concordância que o blog facilitou o processo de aprendizagem do conteúdo de ventilação mecânica.

Ao analisar as respostas para a questão 8 acreditamos que o aparecimento da opção "nem concordo nem discordo" relaciona-se à resposta descritiva dos indivíduos 7-F: "Sua metodologia em sala é ótima, nos ensina com facilidade, porém não gosto de estudar virtual e sim ter em mãos. Boa sorte em sua pesquisa", e 3-M (neste caso não houve resposta descritiva na questão 8 e o indivíduo apresentou a resposta "nem concordo nem discordo" somente na questão 6, no caso de indicação do blog para outros conteúdos e disciplinas. Tem-se, neste caso, uma relação entre a acadêmica 7-F não ter facilidade e não gostar de leituras virtuais, com o fato de manter dúvidas na indicação deste objeto de aprendizagem a colegas e outros conteúdos e disciplinas.

Ao analisar as respostas apresentadas no Gráfico 1 pode-se perceber que não há respostas que vêm ao encontro da discordância das perguntas; ou seja, os quesitos "Discordo Totalmente" e "Discordo" não aparecem. Em relação ao item "Nem Concordo Nem Discordo" houve a ocorrência de três respostas, uma na questão 5 (relacionada à indicação do blog para colegas) e duas na questão 6 (indicação para outros conteúdos e disciplinas). 
Por outro lado, positivamente, a resposta "Concordo", ocorreu na grande maioria com um total de ocorrência de 56 vezes, seguido da resposta "Concordo Totalmente", com uma ocorrência de 39 aparições.

Isso revela que o blog foi bem aceito e, provavelmente, tenha contribuído positivamente para a construção e ampliação do processo de ensino/aprendizagem de ventilação mecânica para os acadêmicos do curso de Enfermagem, após a aula teórica ministrada.

O Quadro 1 a seguir mostra o número de participantes da pesquisa e as respostas em sua cópia fiel dos questionários.

Ao analisar as respostas pode-se detectar a presença de falas positivas, assim como solicitando materiais do próprio autor do blog, outros tipos de materiais em outros formatos que não aqueles presentes na ferramenta. Como exemplo, uma resposta em que a própria leitora não tem afinidade na realização de leituras virtuais, mas relata a facilidade com que foram repassadas as informações em sala de aula. Uma resposta interessante foi do indivíduo 13-M, solicitando que houvessem mais atividades destas no meio universitário.

\section{Quadro 1 - Apresentação das respostas dos questionários em relação à questão dissertativa}

\begin{tabular}{|c|c|}
\hline $\begin{array}{l}\text { PARTICI- } \\
\text { PANTE }\end{array}$ & $\begin{array}{l}\text { QUESTÃO DISSERTATIVA } \\
\text { Qual a sua sugestão para a melhoria desse objeto de aprendizagem? }\end{array}$ \\
\hline $1-\mathrm{M}$ & $\begin{array}{l}\text { "Na minha opinião essa ferramenta está pronta e me ajudou a escla- } \\
\text { recer muitas dúvidas de maneira clara e simples" }\end{array}$ \\
\hline $2-\mathrm{M}$ & $\begin{array}{l}\text { "Seria interessante textos do autor do blog. Se tem, não identifiquei, } \\
\text { no geral muito interessante" }\end{array}$ \\
\hline $7-\mathrm{F}$ & $\begin{array}{l}\text { "Sua metodologia em sala é ótima, nos ensina com facilidade, porém } \\
\text { não gosto de estudar virtual e sim ter em mãos! Boa sorte em sua } \\
\text { pesquisa" }\end{array}$ \\
\hline $12-\mathrm{M}$ & "Aumentar o acesso de estudantes e profissionais" \\
\hline $13-\mathrm{M}$ & "Que houvessem mais atividades assim no meio universitário" \\
\hline $14-\mathrm{F}$ & $\begin{array}{l}\text { "Disponibilizar um material em PDF ou outra forma, pois algumas } \\
\text { vezes é difícil captar todos os detalhes e seria importante ter um ma- } \\
\text { terial de suporte" }\end{array}$ \\
\hline
\end{tabular}

Fonte: Os autores. 


\section{Discussão}

Na visualização gráfica dos resultados apresentados pôde-se perceber que as respostas de maior ocorrência de todas as questões foi "concordo" e "concordo totalmente", seguidas de apenas 3 respostas "nem concordo nem discordo". Em nenhuma das questões houve as respostas "discordo" ou "discordo totalmente

Ao analisar as respostas das questões objetivas verificou-se que os acadêmicos consideraram o blog útil como objeto de aprendizagem. Os conteúdos do blog foram apresentados de forma clara e compreensível, as informações apresentadas de forma didática e que a ferramenta auxiliou na compreensão do conteúdo e facilitou o processo de ensino de ventilação mecânica em UTI.

Demonstrados na análise das respostas, metodologias facilitadoras do ensino e aprendizagem, que permitam aos estudantes saírem da posição passiva, transformando-os em protagonistas do processo, com incentivo ao desenvolvimento crítico e reflexivo no momento de tomar decisões coerentes na prática da Enfermagem e aptos para viver e conviver no mundo cibernético, devem alicerçar o processo ensino e aprendizagem da área. Nesse sentido, Tecnologias de Informação e Comunicação com suas várias possibilidades podem contribuir significativamente.

Para que ocorra uma aprendizagem significativa precisamos entender o processo de modificação do conhecimento, e não de comportamento, reconhecendo a importância que os processos mentais têm nesse desenvolvimento. A teoria de Ausubel baseou-se em uma reflexão específica sobre a aprendizagem escolar e o ensino, em vez de tentar somente generalizar e transferir à aprendizagem escolar conceitos ou princípios explicativos extraídos de outras situações ou contextos de aprendizagem (PELIZZARI, 2002).

O cenário clínico em terapia intensiva geralmente é um local de intenso ritmo de trabalho, em que há pacientes críticos que apresentam instabilidade clínica. A formação em Enfermagem, em processo de mudança, exige que educadores considerem e estimulem os estudantes para a realização de práticas de estudo independente, visando a sua progressiva autonomia intelectual e profissional (BARBOSA; MARIN, 2009), tais como o uso de ferramentas virtuais. 
Um estudo recente demonstrou que alguns participantes, ao serem indagados em relação às dificuldades perante os cuidados com o paciente em ventilação mecânica, percebem que há lacunas a serem transpostas no cuidado a esse sujeito, além de alguma insegurança no manuseio do ventilador, revelando a necessidade contínua de serem realizados cursos de aperfeiçoamento para a equipe (MELO et al., 2014). Reforça, então, a importância de objetos virtuais de aprendizagem tais como o exposto neste estudo.

\section{Considerações Finais}

Levando em consideração o foco principal do estudo - a Influência de um Blog no Ensino de Ventilação Mecânica na Disciplina de Enfermagem no Cuidado a Pacientes de Risco - pode-se apontar que a utilização desse objeto de aprendizagem teve retorno positivo ao considerar as respostas que os acadêmicos relataram ao responder ao questionário.

Em relação à indicação dessa ferramenta para outros conteúdos e disciplinas, as respostas foram unânimes em concordar com esse fato. Quanto à resposta dissertativa (sugestões para melhoria desse objeto) verificaram-se falas positivas, algumas solicitando materiais do próprio autor do blog, conteúdos em outros formatos. Por outro lado, um dos participantes da pesquisa relatou que não apresentava afinidade com leituras virtuais, mas teve facilidade com as informações durante a aula teórica sobre ventilação mecânica em sala de aula. Resposta interessante foi de um indivíduo que solicitou que houvessem mais atividades destas no meio universitário.

Enfim, verificou-se com a aula teórica ministrada e o acesso aos conteúdos que ao término deste estudo ocorreram mais de 230 visualizações da página do blog. Isso mostra a importância de se colocar em prática novas maneiras de docentes, discentes e profissionais da área facilitarem a compreensão do conteúdo de ventilação mecânica em terapia intensiva. Ao término deste estudo pode-se concluir que não somente para o conteúdo de ventilação mecânica esta ferramenta pode ser eficaz e sim para os conteúdos das mais diversas áreas 
de atuação, no sentido de melhorar consideravelmente o processo de ensino/ aprendizagem para conteúdos de difícil compreensão e facilitar e difundir ainda mais os assuntos com maior facilidade de aprendizagem.

Conclui-se, então, que o blog contribuiu positivamente para a construção e para o processo de ensino/aprendizagem de ventilação mecânica para os acadêmicos do curso de Enfermagem, após a aula teórica acerca deste conteúdo, considerado por muitos de difícil compreensão. Tivemos também uma avaliação positiva do blog, pois as respostas dos usuários foram positivas quanto a sua apresentação e construção.

\section{Referências}

ALVAREZ, A. G.; SASS, G. T. M. dal. Objetos virtuais de aprendizagem: contribuições para o processo de aprendizagem em saúde e enfermagem. Acta Paul Enferm., v. 5, n. 24, p. 707-711, 2011.

AUDINO, D. F. Objetos de aprendizagem hipermídia aplicado à cartografia escolar no sexto ano do ensino fundamental em geografia. 2012. Dissertação (Programa de Pós-Graduação em Geografia) - Centro de Filosofia e Ciências Humanas, Departamento de Geociências, Universidade Federal de Santa Catarina, Florianópolis, 2012.

BARBOSA, S. F. F.; MARIN, H. F. Simulação baseada na web: uma ferramenta para o ensino de enfermagem em terapia intensiva. Revista Latino Americana de Enfermagem, v. 17, n. 1, p. $7-13,2009$.

BRAGA, J. C. et al. Desafios para o desenvolvimento de objetos de aprendizagem reutilizáveis e de qualidade. Workshop de Desafios da Computação Aplicada à Educação (DESAFIE-2012). Universidade Federal do ABC - UFABC, Curitiba, 2012. p. 90-99.

CALIL, F. C. et al. A produção científica de objetos de aprendizagem no ensino em enfermagem. J. Health Inform., SIIENF, v. 4, p. 138-143, 2012.

CARNEIRO, M. L. F.; SILVEIRA, M. S. Objetos de aprendizagem como elementos facilitadores na Educação a Distância. Educar em Revista, n. 4, p. 235-260, 2014.

CARVALHO, C. R. R.; FRANCA, S. A.; TOUFEN JUNIOR, C. Ventilação mecânica: princípio, análise gráfica e modalidade ventilatória. Jornal Brasileiro de Pneumologia, v. 33, n. 2, p. 54-70, 2007.

COSTA, D. Fisioterapia respiratória básica. São Paulo: Atheneu, 2004. 
DIAS SOBRINHO, José. Avaliação institucional: notas para pensar o Paiung e o Sinaes. Contexto \& Educação, ano 24, v. 81, p. 133-144, 2009.

FABRE, Marie-Christine J. M.; TAMUSIUNAS, F.; TAROUCO, L. M. R. Reusabilidade de objetos educacionais. Renote, v. 1, n. 1, p. 1-11, 2003.

FRANCESC, P. Educação, tecnologia e avaliação: por um uso pedagógico efetivo da tecnologia em sala de aula. In: UNESCO. Experiências avaliativas de tecnologias digitais na educação [recurso eletrônico]. 1. ed. São Paulo, SP: Fundação Telefônica Vivo, 2016. GIL, A. C. Métodos e técnicas de pesquisa social. São Paulo: Atlas, 1999.

GUERRA, F. M. R. M. et al. Objetos de Aprendizagem Virtuais: revisão de artigos publicados na área da saúde. Colabor@ - Revista Digital da Cva-Ricesu, v. 8, n. 31, p. 1-10, 2014.

GUTIERREZ, S. S. Distribuição de conteúdos e aprendizagem on-line. Renote, v. 2, n. 2, p. 1-14, 2004.

JERRE, George et. al. Fisioterapia no paciente sob ventilação mecânica. Revista Brasileira de Terapia Intensiva, v. 19, n. 3, p. 399-407, 2009.

KOMESU, F. C. Blogs e as práticas de escrita sobre si na Internet. In: Hipertexto $e$ gêneros digitais: novas formas de construção do sentido. Disponível em: <https://www. ufpe.br/nehte/artigos/blogs.pdf>. Acesso em: 18 maio 2017.

KNOBEL, E. Terapia intensiva: pneumologia e fisioterapia respiratória. São Paulo: Atheneu, 2004.

MAGNAGNAGNO, C. C.; RAMOS, M. P.; OLIVEIRA, L. M. P. Estudo sobre o uso do Moodle em cursos de especialização a distância da Unifesp. Revista Brasileira de Educação Médica, v. 39, n. 4, p. 507-516, 2015.

MARIM, V.; FREITAS, A. V.; SANTOS, H. S. Formação de professores na era da inclusão digital. Contexto \& Educação, ano 29, n. 94, p. 153-178, 2014.

MARINHO, S. P. P. Blog na educação e manual básico do blogger. 3. ed. Belo Horizonte: Pontifícia Universidade Católica de Minas Gerais; Instituto de Ciências Humanas; Programa de Pós-Graduação em Educação, 2007.

MEIRELES, G. S.; PARAÍSO, M. A. O currículo dos blogs educativos sobre alfabetização: produção de saberes e modos de subjetivação. Revista Tecnologias na Educação, ano 7, n. 13, p. 1-14, 2015.

MELO, E. M. et. al. Nursing care of hospitalised patients receiving mechanical ventilation in intensive care units. Revista de Enfermagem Referência. Série IV, n. 1, p. 55-62, 2014.

MELLO, G. N. Educação escolar brasileira: o que trouxemos do século XX? Porto Alegre: Artmed, 2004. 
MOREIRA, M. A. Aprendizagem significativa, organizadores prévios, mapas conceituais, diagramas $V$ e unidades de ensino potencialmente significativas. Instituto de Física UFRGS. Material de apoio para o curso Aprendizagem Significativa no Ensino Superior: Teorias e Estratégias Facilitadoras. Porto Alegre: PUCPR, 2013.

NUNES, A. O. et al. Atitudes e crenças sobre as relações CTSA de estudantes do curso de edificações na modalidade EJA: uma análise por períodos. Holos, ano 26, v. 5, p. 244-254, 2010.

PELIZZARI, A. et al. Teoria da aprendizagem significativa segundo Ausubel. Revista $P E C$, v. 2, n. 1, p. 37-42, 2002.

RENGIFO, S. P. Y. et al. Desenvolvimento de objetos virtuais de aprendizagem como uma estratégia para promover a retenção dos alunos no ensino superior. Revista EAN., n. 79, p. 116-129, 2015.

ROCHA, E. P.; OLIVEIRA, A. P. P.; ESTEVES, A. V. F. Validação das tecnologias educacionais na área de Enfermagem: uma revisão integrativa. Scientia Amazonia, v. 4, n. 3, p. 41-47, 2015.

ROSA; F. K. et al. Comportamento da mecânica pulmonar após a aplicação de protocolo de fisioterapia respiratória e aspiração traqueal em pacientes com ventilação mecânica invasiva. Revista Brasileira de Terapia Intensiva, v. 19, n. 2, p. 170-175, 2007.

SALMINEN, L. et al. Nurse teacher candidates learned to use social media during the international teacher training course. Nurse Education Today, v. 36, p. 354-359, 2016.

SOARES, S. R. A. pesquisa como norteadora da formação profissional na universidade Estudos em Avaliação Educacional, v. 24, n. 55, p. 224-245, 2013.

TAROUCO, L. M. R.; et. al. Objetos de aprendizagem para M-learning. In: SUCESU - CONGRESSO NACIONAL DE TECNOLOGIA DA INFORMAÇÃO E COMUNICAÇÃO. Florianópolis, 2004.

TAVARES, R. Aprendizagem significativa. Revista Conceitos, v. 5, n. 10, p. 55-60, 2004.

TRINDADE, C. S.; DAHMER, A.; REPPOLD, C. T. Objetos de aprendizagem: uma revisão integrativa na área da saúde. Journal of Health Informatics, v. 6, n. 1, p. 20-29, 2014.

WILEY, D. A. Learning Object Design and Sequencing Theory. Dissertation Doctor of Philosophy. Department of Instructional Psychology and Technology. Provo - Utah: Brigham Young University, 2000.

YAMASHIRO, N. Manual de instruções de uso: ventilador pulmonar Servoi. Disponível em: <http://www4.anvisa.gov.br/base/visadoc/REL/REL[7441-1-2].PDF>. Acesso em: 19 set. 2017.

ZAMBONI, M. Pneumologia: diagnóstico e tratamento. São Paulo: Atheneu, 2006. 